\title{
Sport medicine and the ethics of boxing
}

Suzanne Leclerc
McGill Sport Medicine
Clinic
475 Pine Ave W
Montreal, Quebec,
Canada H2W 1S4
Christopher D Herrera
Biomedical Ethics Unit
McGill University
Montreal, Quebec,
Canada H2W 1S4
Correspondence to:
Dr Leclerc
suzannel@sportmed.
lan.mcgill.ca
Competing interests:
None declared
This article originally
appeared in Br J Sports
Med 1999;33:426-429

\section{OVERVIEW}

Against commentators who support a ban on boxing, others see the sport as an expression of individual liberty and recommend that the medical community work toward improving safety in boxing. ${ }^{1}$ Defenders of boxing concede, for instance, that beating the opponent's head is the standard route to victory. They may even admit that this poses health risks. Where both sides in this debate become wary is at the thought of physicians interfering in the lifestyle choices of athletes. In the light of this apprehension, the moral options for sport physicians deserve examination.

Exact figures on the prevalence of boxing injuries are hard to find and often do not distinguish between injuries attributable to boxing and those exacerbated by the physical contact, even in training. Also, whether professional boxing should be considered in the same analysis with amateur boxing is debatable. ${ }^{2}$ Having said this, we generally accept the survey of the health risks that Ryan $^{3}$ and Cantu ${ }^{4}$ provide, which shows that concussion and brain damage are the most prominent dangers. Conceding that much research still needs to be done before we can know with certainty the nature of boxing injuries, it is safe to say that human anatomy is at odds with the preferred tactic in boxing, which is to strike the opponent's head.

\section{THE ETHICAL CASE FOR PHYSICIAN ACTION Paternalism}

This raises an obvious question of what physicians should do in response to the medical evidence. Should they continue to treat boxing injuries and perhaps work toward reform of the rules and equipment of the sport? Or should physicians take a stronger stand against boxing? Some commentators worry about the latter course. They contend that physicians who try to prevent boxing injuries can easily abuse their power and good intentions. The traditional concern, not unique to sport medicine, is paternalism-that is, "how to get people to do what is good for them without tyrannizing them." ${ }^{(p 26)}$ In the boxing debate, such concern focuses on whether physicians would know when to put the brakes on. "If we are to prevent young boxers from hitting each other," one critic claims, "consistency seems to demand that we should also prevent them from engaging in a variety of other activities which are as dangerous ... as boxing." 6(p59) Another critic asks if the next step would be to ban birth control and "gay lifestyles."7 To this end, critics claim that legal restrictions would

\section{Summary points}

- Sport physicians are uniquely situated to assess and act on the evidence of health risks to boxers

- Given the apparent risk of permanent brain damage, sport physicians should take a public stand against this sport, to the extent that therapeutic obligation permits

- This should include efforts to educate the public and an open disassociation from the sport

unduly infringe on the boxers' autonomy. They typically cite 19th century philosopher John Stuart Mill, who offers a strong libertarian argument against restricting private behavior. ${ }^{8}$

On the traditional interpretation, Mill would allow a person to engage in nearly any behavior, so long as it was freely chosen and did not infringe on the autonomy of others. With this interpretation in mind, commentators argue that boxers should be, at most, advised of the risks of boxing and left to decide for themselves whether to box. Still, a critique of boxing need not amount to physician tyranny or autonomy infringement. The interpretation of autonomy, and its application to the problem of boxing, is more complicated than libertarian slogans let on. In particular, the critique of boxing can represent the fusion of medical and ethical judgment that arises from any definition of sport. That is, society relies on physicians to assist in setting limits on what constitutes permissible sport. Hence, there is nothing unusual or dangerous about their offering guidance on the health-related aspects of boxing.

Indeed, Mill's theory of individual freedom actually calls the ethics of boxing (not its legal status) into question. Mill feared state intervention into private affairs because he thought that "some projects are more worthy than others, and liberty is needed precisely to find out what is valuable in life, to question, re-examine, and revise our beliefs about value." 9 (p18) The idea is that if autonomy is deemed important, it has to matter what effect the sport of boxing has on a boxer's ability to direct his or her life, including decisions about participating in boxing. Hence, on the assumption that medical evidence adequately shows that there is a risk that boxers might, through ordinary training and competition, diminish their own ability to select 
goals and to apply methods of attaining them, this evidence supports a strong condemnation of the sport.

Attempts to apply Mill's account of autonomy to matters of personal health are problematic because his views on political liberty are somewhat opposed by his views on personal responsibility for health. ${ }^{10}$ Nonetheless, libertarians clearly cannot have it both ways. Once we allow respect for autonomy into the calculation, regardless of which definition of autonomy we adopt, we must cater as well to the preconditions for that autonomy. It is significant, therefore, that libertarians advocate personal freedom because it enables citizens to refine their goals. A condemnation of boxing is consistent with this. As long as physicians restrict themselves to medical advocacy, there is little risk of autonomy infringement. Also, aside from what sport physicians say about boxing, ultimate control over paternalism resides with elected officials and legislators, who, unlike physicians, make and enforce laws.

\section{Obligations and expertise}

Physicians of other specialties attempt to influence public attitudes about such things as smoking, handguns, and improper diet. Admittedly, this creates an ambiguous public role, and the history of physician activism is a checkered one. One historian notes, for instance, that the same medical associations that successfully campaigned against women's corsets as being unhealthy for respiration helped convince the public of a "link" between female masturbation and insanity. ${ }^{11}$ The lesson from episodes like this is that sport physicians must combine the courage to be wrong with the conscience to amend a position as evidence accumulates. As always, physicians will have to make decisions about boxing amid shifting clinical and social contexts. ${ }^{12}$ But neither the difficulty in knowing the optimum level of physician responsibility nor the problem in achieving certainty about boxing's risks should preclude action.

Physicians routinely take risks of their own when they decide to put their efforts toward the repair or the prevention of injuries in boxers and other athletes. Here, too, a critical stance against boxing is a logical extension of this process. We suggest a stance against boxing that requires not omniscience, but a presumption of greater knowledge of the specific risks involved. ${ }^{13}$ In a similar way, the existence of prescription drug laws does not indicate that physicians always know more than patients, only that they know more about specific drugs and their effects. We advocate an approach to the boxing issue based on what Hauerwas labels "fallible medicine," ${ }^{14}$ whereby physician and patient assume incomplete knowledge at the outset. This has both partners recognizing the possibility of minor oversight. ${ }^{14}$ Under this physician-patient model, the sport physician would strive to educate as well as treat patients, with the assumption that "to be autonomous, one must be informed." 15 (р330)

In this light, physicians who let patients reason in what amounts to a state of ignorance or misinformation are as irresponsible as those who would try to impose idiosyncratic values on the lifestyle choices of patients. Where they know of avoidable health risks, such as those associated with boxing, sport physicians have to do more than present facts. They must present conclusions based on those facts, even if this sometimes casts a negative light on certain behaviors.

\section{PROBLEMS WITH THE REFORMIST POSITION}

This returns us to the issue of what precisely sport physicians ought to do. All sports represent a compromise in personal freedom and safety between the need to pursue enjoyable and lucrative activities and the need to avoid injury. By convention, physicians join society in drawing the line when it comes to how injuries may occur and how to reduce the risk. In hockey and football, research into the nature and prevention of head injuries has led to rule and equipment changes. ${ }^{16}$ These changes, the result in part of physician intervention and advice, have made it possible to retain the essential nature of these contact sports without endangering players' heads. ${ }^{17}$

Should sport physicians, therefore, work to reform boxing? This is a hard question to answer because it is doubtful that reform will solve the medical and moral problems in boxing. ${ }^{18}$ Past efforts have ranged from prohibiting punches below the belt (the Broughton rule of 1743) to more sweeping rule changes against holding, butting, gouging, kicking, and the wearing of spiked shoes. In 1866 the Marquis of Queensbury rules called for the wearing of gloves in all bouts, a 10-second count after a knockdown, and fighters to be matched within weight categories. Later reformers limited the number and length of rounds and awarded broader discretionary power to referees. With additional reform, medical evaluations and the wearing of mouthpieces became standard, and some states, such as New York, have taken steps to reduce injuries further. ${ }^{19,20}$

Unfortunately, refinement of diagnostics and improved education of boxers, trainers, and ringside doctors will take us only so far. What will persist is the boxer's underlying goal: the contest often goes to the boxer who can punch the opponent into submission or unconsciousness. In matches based on points, the decision often goes to the boxer who excels in aggressiveness and injures or knocks down the opponent through punches to the head. In professional boxing, the incentive is direct: the scoring and ranking system gives priority to the fighter who is able to knock the opponent out. (The differences between amateur and professional boxing vary by country. The official versions of the scoring and rule differences in Canadian boxing are available on the web sites of the Canadian Amateur Boxing Association [www.boxing.ca] and the United States Amateur Boxing Association [www.usaboxing.org].) Even in amateur boxing, where the knockout is less common, there is still a risk of concussion from blows to the head. Hence, in amateur or professional boxing, what would reform ultimately involve? Would the fight need to be stopped after each punch to diagnostically assess the trauma?

\section{CONCLUDING RECOMMENDATIONS}

The obvious and more practical solution would be along the lines of rule changes that may penalize punches to the head. This would no doubt reduce some health risks. ${ }^{21}$ The rule changes would at the same time create a substantially different sport and leave open the question of whether the new boxing would be an athletic activity that sport physicians should welcome as "reformed." Would it be ethically improved, for example, if some other body part were the target area for scoring in boxing? This matter aside, the prudent option seems to be for sport physicians to work with athletes and society and to reevaluate the idea that sport should involve people battering each other until one of them can no longer go on or until the body is damaged. 
The reformist view holds that the sport medicine community can take other practical steps. Should the consent forms used with boxers be improved? This idea has merit, but questions about what boxers would consent to would remain. In medicine and law, the consent form usually reflects nonmaleficenceprotecting the patient from unanticipated risks. The best consent form would perhaps waive a boxer's entitlement to nonmaleficence, even to protection from self-imposed harm. Nevertheless, at risk is not only the boxer's body but also that of the opponent. Clarifying the idea of a person consenting to harm another person and to be harmed in the process is no simple matter. This complexity only confirms that a signed consent form is never the same as ethical closure.

For their part, the major medical associations appeal to legislative authority to ban boxing. For a number of reasons we offer only qualified support for these efforts. First, talk of a ban should be accompanied by a willingness in the sport medicine community to reform or reinstate boxing if new evidence supports this. Second, the community needs to work toward broad changes in public attitudes about boxing and, equally important, the sport physician's role in it. We maintain, therefore, that the sport physician should assume a greater role in educating the public, not simply boxers, of the risks involved. This should include repeated, consistent scrutiny of the preventive measures that have been proposed thus far, such as protective equipment and even routine medical screenings.

We also urge a more overt step: for sport physicians to refuse direct participation in boxing. The mere presence of a sport physician at a boxing match lends an air of legitimacy to behavior that is medically and ethically unacceptable. The absence of the "fight doctor" at ringside would send a strong, clear message to those affiliated with boxing. Physicians of any specialty should continue to treat those who are injured. In those efforts, the distinction between direct and indirect participation would probably prove difficult to establish. ${ }^{22}$ Nevertheless, we suggest that there are ways to discharge the therapeutic obligation without going near the boxing ring.

A discontinuation of open participation with boxing would be an expression of the physician's right to act on values or interests that are important for the profession and the preservation of physician autonomy. One physician who had reservations when a patient asked for medical certification to box describes the essence of this right. "The human cranium is not designed to have repeated blows directed at it," he explains, "and is likely to be damaged by a sport where this is the main aim." ${ }^{23(p 69)}$ In the end, he decided that: doctors have rights too, and why should I spend the weekend worrying about his cauliflower ears and subdural hemorrhage? So like Pontius Pilate I washed my hands (a well-known medical ploy to gain time) and in the eleventh minute told him that I had no intention of signing his form, and that if he insisted on damaging his, or someone else's brain, then he must find another medical accomplice.

There is precedent for the avoidance of any connection with boxing in the near-unanimous position against physician involvement in capital punishment. ${ }^{24,25}$ There, physicians who have significant moral objections to state-sponsored executions have taken a visible stand against any association that the practice may have with the medical community. Clearly, there are differences in severity between these 2 cases, but the principle is the same: physicians are entitled to obey their own consciences, which may include taking unpopular stands for the good of the profession and their patients. In particular, sport physicians and others in health care who best understand the mechanism for boxing injury can end their direct involvement with boxing, on the grounds that participation is contrary to the goal of improved public health and their personal integrity.

Contributors: C D H coauthored the article. S L coauthored the article and presented a version of it to a McGill University seminar on bioethics theory.

References

1. Cantu RC. How to make boxing safer. In: Boxing and Medicine. Champaign, IL: Human Kinetics; 1995:187-195.

2. Lundberg GD. Boxing should be banned in civilized countries: round 3 [Editorial]. JAMA 1986;255:2483-2485.

3. Ryan AJ. Intracranial injuries resulting from boxing. Clin Sport Med 1998; 17:155-168.

4. Cantu RC. Brain injuries. In: Boxing and Medicine. Champaign, IL: Human Kinetics; 1995:19-31.

5. Kass LR. Regarding the end of medicine and the pursuit of health. In: Caplan AL, Englehardt HT, McCartney JJ, eds. Concepts of Health and Disease: Interdisciplinary Perspectives. Reading, MA: Addison-Wesley Publishing; 1981:3-30.

6. Warburton N. Freedom to box. J Med Ethics 1998;24:56-60.

7. Fiore DC. Boxing: does the size of the prize affect the drain on the brain? [Letter] JAMA 1996;276:954.

8. Patterson RH Jr. On boxing and liberty. JAMA 1986;255:2481-2482.

9. Kymlicka W. Liberalism, Community, and Culture. New York: Oxford University Press; 1991.

10. Childress JF. Who Should Decide? Paternalism in Health Care. New York: Oxford University Press; 1982:191-202.

11. Duffy J. The physician as a moral force. In: Bondeson WB, Englehardt HT, Spicker SF, et al, eds. New Knowledge in the Biomedical Sciences: Some Moral Implications of Its Acquisition, Possession, and Use. Dordrecht, Netherlands: Kluwer Academic Publishing; 1982:3-21.

12. Maseide P. Possibly abusive, often benign, and always necessary: on power and domination in medical practice. Sociol Health Illness 1991;13:545-561.

13. Rainbolt GW. Prescription drug laws: justified hard paternalism. Bioethics 1989;3:45-58.

14. Hauerwas SM. Authority and the profession of medicine. In: Agich GJ, ed. Responsibility in Health Care. Dordrecht, Netherlands: Kluwer Academic Publishers; 1982:83-104.

15. Savulescu J. Rational non-interventional paternalism: why doctors ought to make judgments of what is best for their patients. $J$ Med Ethics 1995;21:327-331.

16. Honey CR. Brain injury in hockey. Clin J Sport Med 1998;8:43-46.

17. Kelly JP, Rosenberg JH. The development of guidelines for the management of concussion in sports. J Head Trauma Rehabil 1998; 13:53-65.

18. Gillon R. Doctors should not try to ban boxing - but boxing's own ethics suggests reform [Editorial]. J Med Ethics 1998;24:3-4.

19. Lundberg GD. Blunt force violence in America - shades of gray or red: ultimate/extreme fighting [Editorial]. JAMA 1996;275:1684-1685.

20. Jordan BP. Professional boxing: experience of the New York state athletic commission. In: Cantu RC, ed. Boxing and Medicine. Champaign, IL: Human Kinetics; 1995:177-185.

21. Pearn J. Reducing brain damage in boxers [Letter]. Med J Aust 1998;168:418.

22. Loewy EH. Ethical Dilemmas in Modern Medicine: A Physician's Viewpoint. Lewiston, NY: Edwin Mellon Press; 1986.

23. Toon PD. Boxing clever. J Med Ethics 1988;14:69.

24. Council on Ethical and Judicial Affairs. Physician participation in capital punishment. JAMA 1993;270:365-368.

25. Truog RD, Brennan TA. Participation of physicians in capital punishment. N Engl J Med 1993;329:1346-1350. 